\title{
Brief Report: A Reappraisal of Clumsiness as a Diagnostic Feature of Asperger Syndrome
}

\author{
Mohammad Ghaziuddin, ${ }^{1}$ Luke Y. Tsai, and Neera Ghaziuddin \\ University of Michigan, Ann Arbor
}

Asperger syndrome, first described by the Austrian physician Hans Asperger (1944), is an uncommon disorder whose clinical features overlap with those of autism (Kanner, 1943) and schizoid personality disorder (Wolff \& Barlow, 1979; Wolff \& Chick, 1980). Some authorities regard it as part of the "autistic spectrum" (Wing, 1981), while others have argued for the need to separate it from autism (Rutter, 1988; Tsai, 1991).

One possible reason for the controversy surrounding the status of this syndrome is the lack of consensus about its clinical features. It is generally accepted that the core features of the syndrome consist of social isolation, odd and pedantic speech, poor nonverbal communication, and preoccupation with certain idiosyncratic interests (Wing, 1981). In addition, clumsiness has been proposed as one of the diagnostic criteria. Thus, based on the description of cases by Asperger, Wing (1981) noted that gross motor movements are clumsy and ill-coordinated in this syndrome. Most of the patients are said to be poor at games involving motor skills, and sometimes show impaired ability to write and draw. In a subsequent paper (Burgoine \& Wing, 1983), she stated that "clumsy and ill-coordinated movements and odd posture" form one of the major clinical features of Asperger syndrome [italics added]. Other writers have concurred with this view. For example, after a review of the topic, Tantam suggested that the diagnosis of Asperger syndrome should be used for those autistic children who "use language freely but fail to make adjustment to fit different social contexts or the needs of different listeners, wish to be sociable but fail to make relation-

\footnotetext{
${ }^{1}$ Address all correspondence to Mohammad Ghaziuddin, Department of Child and Adolescent Psychiatry, University of Michigan Hospital, Taubman Center Box 0390, 1500 East Medical Center Drive, Ann Arbor, Michigan 48109-0390.
} 
ships with peers, develop idiosyncratic but engrossing interests, have marked impairments of nonverbal expressiveness and are conspicuously clumsy" (Tantam, 1988a, p. 252 [italics added]). While the DSM-III-R (American Psychiatric Association [APA], 1987) has no special category for this syndrome, the proposed ICD-10 (World Health Organization [WHO], 1987) has included it as a subtype of pervasive developmental disorders. The ICD-10 also mentions clumsiness as a feature of this syndrome, with the caveat that it is not essential for diagnosis. Thus, clumsiness is increasingly being accepted as a typical feature of this syndrome. The purpose of this brief report is to examine this issue. Specifically, it attempts to examine how clumsiness has been defined and assessed in the literature on Asperger syndrome.

\section{METHOD}

All publications which included the term "Asperger syndrome" in their title were identified with the help of a computer-assisted search. Only articles published in English were examined with the exception of Asperger's original description (1944) as quoted by Wing (1981). With the help of cross-references it was inferred that no papers on the prevalence of clumsiness in Asperger syndrome have been published in the non-English literature. Articles published under the title of autistic psychopathy were also included as this was the title used by Asperger in his first paper.

Studies were categorized in the following manner: (a) those which defined clumsiness and dealt specifically with this symptom; (b) those which listed clumsiness as a feature (diagnostic or otherwise) of the syndrome; and (c) those which described its assessment by standardized tests. For the purpose of this report, clumsy, uncoordinated, and ill-coordinated were regarded as interchangeable terms. However, such descriptions as "large and clumsy gestures" and "awkward social graces" were not regarded as synonymous with motoric clumsiness.

\section{RESULTS}

A total of 42 papers on Asperger syndrome were identified (you may contact the first author for a list of these papers). Twenty of these were case reports; 10 were case-control studies; and the rest were case series, epidemiological comments, and so forth.

None of the publications defined clumsiness. Twenty-three publications mentioned it as a feature of the syndrome, out of which 11 were case 
reports. Only a few of these publications clearly stated that they had used clumsiness as a diagnostic criterion while others mentioned it as an incidental finding. Only 4 publications clarified that they had used tests specifically for the purpose of assessing clumsiness or motor coordination (Gillberg, 1989; Szatmari, Bartolucci, \& Bremner, 1989; Szatmari, Tuff, Finlayson, \& Bartolucci, 1990; Tantam, 1988c).

\section{DISCUSSION}

The findings suggest that, despite the generally accepted view that clumsiness is associated with Asperger syndrome, few studies have examined this issue in detail. None of the studies offered an operational definition of clumsiness. One reason for this lies in the fact that clumsiness is a comparative concept and is difficult to define. There is no absolute measure of clumsiness and some studies have found rather low agreement among professionals for its identification (Keogh, Sugden, Reynard, \& Calkins, 1979). A clumsy child can be described as one whose ability to perform skilled purposive movement is impaired, yet whose motor coordination is virtually normal by the standards of routine, conventional neurological assessment (see Gubbay, 1985). Clumsy children are relatively slow and inaccurate in all types of perceptual-motor skills. They have difficulties with acquisition of skills such as constructing models, writing, hopping, cycling, and throwing or catching a ball. While no consensus exists about its exact definition, it may be defined as an impairment of motor skills on standardized tests of motor impairment, below the expected level of intelligence, in the absence of a known neurological disease. Thus, the degree of clumsiness can be modified by a variety of factors including global mental retardation. Yet, despite the fact that patients with Asperger syndrome may also have coexisting mental retardation (Wing, 1981), the role of low IQ does not appear to have been taken into consideration while classifying patients as clumsy (e.g., Carpenter \& Morris, 1990). In addition, clumsiness is not specific to Asperger syndrome. Autistic children may also show problems with motor skills (DeMyer, 1976). Troublesome clumsiness may occur in about 2 to $5 \%$ of normal children, more often boys than girls (Gardiner-Medwin, 1987). It may occur as a nonspecific finding in children and has also been described in association with certain psychiatric conditions such as developmental expressive and receptive language disorders (APA, 1987). Thus, it is unclear to what extent this symptom should be regarded as having a special association with Asperger syndrome.

Furthermore, almost one half of the publications did not mention clumsiness, either as a diagnostic feature or as an incidental finding. It is 
possible that even this figure is an overestimate as sometimes multiple studies originated from the same sample. Also, some of the studies did not clearly differentiate between autism and Asperger syndrome in their samples (e.g., Tantam, 1988b, 1988c); while others made only a passing reference to the presence of this symptom.

The other issue that was not adequately considered is the assessment of clumsiness. Only four studies used tests to measure this symptom. In one study (Gillberg, 1989), a cutoff score of 15 and above on the performance subscale of Griffith's scale was used to classify patients as clumsy; however, the rationale for using this as the cutoff point was not explained. In another study (Tantam, 1988c), subjects were timed while attempting to stand on one leg with their eyes closed and were also required to catch a paper ball thrown; however, this study did not clearly differentiate between autism and Asperger syndrome in the sample of 41 subjects. In the third study (Szatmari et al., 1989), subjects were asked to perform five tasks, namely, ability to dress, tie shoelaces, eat with utensils, use pencils, and do puzzles; however, it is not clear if any of these tests were standardized. In many cases, the decision whether or not the person was clumsy was made based entirely on the clinician's subjective impression. Some reports apparently based their diagnosis of clumsiness on the results of IQ tests. However, these tests are not standardized for this purpose as are, for example, the Test of Motor Impairment (Stott, Moyes, \& Henderson, 1984) or those used by Gubbay (1975). If clumsiness is indeed an important feature of Asperger syndrome, it is crucial that it is not only properly defined but also properly assessed.

In addition, no attempt was generally made to differentiate between clumsiness in the upper limbs from that in the lower limbs. For example, one study (Szatmari et al., 1989) assessed clumsiness by examining five items, all of which dealt with coordination in the upper limbs. It is conceivable that a person may have difficulty in performing fine motor tasks with his hands but have no impairment in the coordination of his lower limbs while another may have an awkward gait and run into objects while walking but show no other features of clumsiness.

The question of age has not been considered in the diagnosis of Asperger syndrome using clumsiness as a criterion. This is important because autistic children also tend to have problems with coordination as they reach adolescence (Wing, 1981). Thus, even if it is true that Asperger patients are usually clumsy, this may apply more to preadolescents. Allowance should, therefore, be made for the variable of age in any system that uses clumsiness as a criterion for the diagnosis of Asperger syndrome.

In conclusion, based on the existing literature, it appears that the symptom of clumsiness in Asperger syndrome has not been adequately 
studied. While it may not be a major diagnostic feature, it may occur as an associated finding or as a component of a set of multiple deficits that is specific to Asperger syndrome and that distinguishes it from other disorders. Future studies should, therefore, attempt to study this problem in a systematic manner. An operational definition of clumsiness should be adopted and standardized tests used for its assessment. The effect of age and general level of cognitive functioning on the measurement of this symptom should also be taken into consideration. Finally, as clumsiness can be found in normal as well as in other psychiatric populations, comparative studies should be undertaken to find out if this symptom indeed has a special relationship with Asperger syndrome.

\section{REFERENCES}

American Psychiatric Association. (1987). Diagnostic and statistical manual of mental disorders (3rd ed., rev.). Washington, DC: Author.

Asperger, H. (1944). Die autischen psychopathen im kindesalter. Archiv fur Psychiatrie Und Nervenkrankheiten, 117, 76-137.

Burgoine, E., \& Wing, L. (1983). Identical triplets with Asperger's syndrome. British Journal of Psychiatry, 143, 261-265.

Carpenter, P. K., \& Morris, D. (1990). Association of Acrocyanosis with Asperger's syndrome. Joumal of Mental Deficiency Research, 34, 87-90.

DeMyer, M. (1976). Motor, perceptual and intellectual disabilities of autistic children. In L. Wing (Ed.), Early childhood autism. Oxford, England: Pergamon.

Gardiner-Medwin, D. (1987). Developmental abnormalities of the nervous system. In D. J. Weatherwell, J. G. G. Ledingham, \& D. A. Warrel (Eds.), Oxford Text Book of Medicine (Vol 2, p. 21.205, 2nd.). Oxford, England: Oxford University Press.

Gillberg, C. (1989). Asperger syndrome in 23 Swedish children. Developmental Medicine and Child Neurology, 31, 520-531.

Gubbay, S. S. (1975). The clumsy child. Philadelphia: Saunders.

Kanner, L. (1943). Autistic disturbances of affective contact. Nervous Child, 2, 217-250.

Keogh, J. F., Sugden, D. A., Reynard, C. L., \& Calkins, J. A. (1979). Identification of clumsy children: comparisons and comments. Joumal of Human Movement Studies, 5, 32-41.

Rutter, M. (1988). DSM-III-R: A postscript. In M. Rutter, A. H. Tuma, \& I. S. Lann (Eds.), Assessment and Diagnosis in Child Psychopathology. New York: Guilford.

Stott, D., Moyes, F. A., \& Henderson, S. E. (1984). Manual of Test of Motor Impairment Henderson revision. Ontario: Brook Educational.

Szatmari, P., Bartolucci, G., \& Bremner, R. (1989). Asperger's syndrome and autism: Comparison of early history and outcome. Developmental Medicine and Child Neurology, 31, $709,720$.

Szatmari, P., Tuff, L., Finlayson, A. J., \& Bartolucci, G. (1990). Asperger's syndrome and autism: Neurocognitive aspects. Joumal of the American Academy of Child and Adolescent Psychiatry, 29, 130-136.

Tantam. D. (1988a). Asperger's syndrome: Annotation. Joumal of Child Psychology and Psychiatry, 29, 245-255.

Tantam, D. (1988b). Lifelong eccentricity and social isolation. I. Psychiatric, social and forensic aspects. British Journal of Psychiatry, 153, 777-782.

Tantam, D. (1988c). Lifelong eccentricity and social isolation. II. Asperger's syndrome or schizoid personality disorder. British Journal of Psychiatry, 153, 783-791. 
Tsai, L. (1991). Other pervasive developmental disorders. In J. Weiner (Ed.), Comprehensive text book of child and adolescent psychiatry. Washington, DC: American Psychiatric Press.

Wing, L. (1981). Asperger's syndrome: a clinical account. Psychological Medicine, 11, 115-129.

Wolff, S., \& Barlow, A. (1979). Schizoid personality in childhood: A comparative study of schizoid, autistic and normal children. Journal of Child Psychology and Psychiatry, 20, 2946.

Wolff, S., \& Chick, J. (1980). Schizoid personality in childhood: A controlled follow-up study. Psychological Medicine, 10, 85-100.

World Health Organization. (1987). International classification of diseases, 10th rev., draft). Geneva: Author. 